\title{
The Risk Assessment of the Fog Disaster in Beijing
}

\author{
Haibo Hu${ }^{1}$ Jinjun Pan ${ }^{2}$ \\ ${ }^{1}$ The institute of urban meteorology, CMA, Beijing 100089, China \\ ${ }^{2}$ The Beijing meteorological bureau, Beijing 100089, China
}

\begin{abstract}
The fog probability in urban area is determined by the observatory data. Taking the regular grid to be the assessed unit, the Fragility Exponential (FE) is computed upon the gird cell, in which the density of the road-net is stood for, and the FE can be modified according to the important facility distributed on the grid cell. The population density is utilized as the index of vulnerability. Moreover, the probability, fragile, and vulnerability is composed by 5:2:1 to integrally measure the risk index of fog in urban area. The example use nearly 10 years observatory data of fog in Beijing district to assess the disaster's risk by spatial grid. The result indicates that the high risk area is consistent to the extending of highway and ring-roads, as parts of urban center area and airport, and so on.
\end{abstract}

Keywords: The fog in urban area; Probability; Fragility; Vulnerability; The risk assessment

\section{北京地区大雾灾害风险评估*}

\author{
扈海波 $^{1}$ 潘进军 $^{2}$ \\ ${ }^{1}$ 中国气象局北京城市气象研究所, 北京 100089 , 中国 \\ 2 北京市气象局, 北京 10089 , 中国
}

摘要：选用大雾观测资料测算城市地区的雾灾危险性指数，以规则网格作为评估单 元，逐网格计算网格区域内的路网密度，以此作为雾灾的空间脆弱性指标，并针对 重点设施的分布情况对脆弱性指数进行空间叠加订正; 选用网格内的人口密度作为 雾灾的易损性指标; 危险性、脆弱性及易损性按 5: 2: 1 的分配比例综合测算雾灾 的风险指数。实例研究选用北京地区近 10 年大雾资料按空间网格化评估方法对大

*北京市科技计划项目 “城市突发气象灾害风险防范与快速响应关键技术研究”（Z090506016609001）、北京 市自然科学基金 “空间改造 GP 适用与城市气象灾害评估的关键问题研究” (9102009) 项目资助.扈海波, 男,1970 年 8 月出生,副研究员,博士,地图学与地理信息系统专业,主要研究方向为城市气象灾害、GIS 理论及应 用。 
雾灾害风险进行评估, 结果表明: 北京地区雾灾脆弱性指数的强弱分布与高速路及 环城路延伸方向一致, 高速路段、环城路、市中心及机场等地段为雾灾的高风险区 域, 北京东南部地区的雾灾风险也相对较高。

关键词：城市大雾; 危险性; 脆弱性; 易损性; 风险评估.

\section{1. 引言}

城市是经济实体集中分布的地区，加 之城市交通网密集, 工矿企业及各种 交通工具大量排放污染气体及尾废 气，致使空气中的烟尘污染物等类似 凝结核物质浓度加大。王继志等

（2002）认为随着城市的发展，城市 排放作用所产生的大气污染物在城市 及周边地区的聚集, 加剧雾的生成, 城市雾的强度在逐渐加大 ${ }^{[2]}$ 。“城市 雾” 对城市居民生活质量和安全均带 来较大的影响, 尤其对城市交通及居 民出行造成不利, 甚至出现人员伤亡 事故。例如，2006 年 1 月在京沈高速 公路, 就因大雾的原因发生一起 60 余 辆车追尾相撞 2 人死亡, 10 余人受伤 的严重交通事故。“雾” 被称为天气 杀手, 是一种重要的城市气象灾害风 险源。

从现有文献资料来看，有关大雾 灾害风险评估的研究不多。Kanplan 的 气象灾害风险评估三元组理论的基本 要求是 “有那些不利的天气条件” 、

“出现不利天气条件的可能性” 及

“不利天气条件出现后所造成的影 响” ${ }^{[3]}$ ，后两项表明一个概念一一灾害
危险性评估, 这是风险评估的核心。 一些文献采用多年气象资料分析特定 地区所属特定路段的雾的气候特征， 归纳分析大雾天气的年季、季节、昼 夜等变化特征 ${ }^{[4][5]}$, 这对揭示雾的规律 性认识是有意的, 对风险评估也有借 鉴，但要揭示城市雾灾的真实风险仍 需在此基础上作更深一步的工作。城 市雾灾的风险评估除了要分析雾的气 候统计学特征及规律外, 还应着重剖 析城市特殊功能及结构对大雾天气导 致灾难性事故的响应机制, 比如, 城 市交通路网密度、城市人口密度等指 标所呈现的城市承灾体脆弱性或易损 性分析。分析需要提取城市路网密 度、长度、道路路面空间占有率及城 市人口密度等指标, 这些均可在 GIS 的支持下，通过空间网格分割下的空 间叠置计算得到。

本文尝试在空间信息技术支持 下, 提取一定大小的网格单元的城市 路网特征参数, 按一定权重系数方程 换算路网密度条件下的雾灾脆弱性指 数, 并叠加上基于 10 年（1996-2006） 统计资料得出的大雾的危险性及体现 城市人口密度的易损性指数，综合测 算城市雾灾的风险指数。 
2. 方法与步骤

2.1 危险性评估

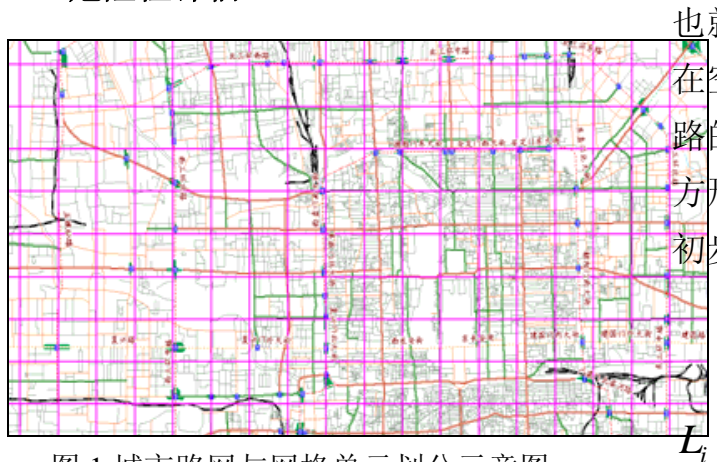

图 1 城市路网与网格单元划分示意图

在研究区域范围内划分一定大小 的正方形网格单元（图 1)。选用多年 的大雾观测资料, 分析大雾的年月际 的变化情况, 并根据每个测站的年平 均大雾日数, 做出大雾在城市地区的 年平均日数分布图, 年平均日数值内 插到每个评估网格单元, 每个网格单 元内的年平均日数与最大年平均日数 的比值作为网格区域内可产生雾灾的 危险性指数, 归一化指数方程表示为

$$
D_{\text {网格 }}=\frac{C_{i}}{C_{\text {max }}}
$$

$C_{i}$ 为该网格内插后的年平均雾日 数, $C_{\text {max }}$ 为所有网格的最大年平均雾 日数。

\section{2 脆弱性评价}

网格单元面与城市基础地理信息 底图上的交通线路作 “空间交” 计 算, 得到每个网格单元内不同道路类 型的路线长度, 以此核算路网密度。 鉴于城市道路类型不一样，其交通拥
堵状况不一, 同等强度的大雾对不同 道路类型的交通造成的影响不一样， 也就是雾灾的响应程度不一样, 因此 空间交计算结束后, 需要按不同道 路的类型及道路的长度核算 “网格正 形” 内包含的路网信息, 即可作为

$$
R_{\text {网格 }}=\sum_{i=1}^{n} L_{i} \times W_{i}
$$

为网格内道路类型 $i$ 的长度, 道路 类型可为 “高速路、一级道路” 等, $W_{i}$ 为道路类型 $i$ 的权重参数。

最后将单网格路网统计参数 $R_{\text {网格 }}$ 进行归一化, 即得到每个网格单元的 路网密度系数, 这个系数为城市道路 系统响应雾灾的脆弱性指标值, 不同 网格的脆弱性指标值的空间分布在 GIS 中是一种空间图谱化结果（图 3)。

\section{3 大雾易损性加权订正}

雾灾的易损性与城市人口分布指 数 (人口密度、人口数量) 等相关, 甚至包括对大雾特别敏感的重要设 施, 比如机场、港口、车站等的分 布。有关人口分布指数的网格化计算 方法已有成熟的空间离散化计算方 法, 其应用方法可参考文献[6][7], 其 中人口分布指数的空间网格与脆弱性 指数的计算网格在空间地理坐标、尺 度大小上是一一对应的（图 3），但对 类似机场等重要设施响应雾灾害的易 损性指数订正时的网格计算, 需要在 方法上做出微小的调整。文献[8][9]在 针对重点设施的易损性评价时, 是依 据区域的统计方法来核算的, 即某个 
区域内的重点设施越多，该区域的易 损性基数就越大。这种方法只适合区 域的易损性指数划分, 而 $1 \mathrm{KM}^{*} 1 \mathrm{KM}$ 小尺度网格区域与这类设施在空间上 可互为叠置 (INTERSECT)，核算小 尺度网格在空间上包含或交叠的重点 设施，比如包含机场后的易损性指 数, 完全可采用空间交运算算出待评 估网格与这类设施的空间相交面积， 然后乘上权重系数, 即可得到网格区 域易损性对重点设施的订正结果, 即

$$
F_{\text {网格 }}=M_{\text {网格与重点设施相交面积 }} \times R_{\text {权重 }}
$$

图 3 为脆弱性指数网格图的易损性订 正结果, 可看出 “机场” 及附近区域 在订正后的脆弱性指数明显增强（图 3 的 $\mathrm{A}$ 部分）。

\section{4 大雾灾害风险指数测算}

大雾灾害风险指数的测算综合雾 灾的危险性、脆弱性指数及易损特征 参数, 测算方法以网格评估单位进行 单一网格内各指数数值的综合叠加, 叠算公式如下

$$
R_{\text {total }}=D_{\text {网格 }} \times W_{1}+R_{\text {网格 }} \times W_{2}+F_{\text {网格 }} \times V
$$

有关 $W_{1} 、 W_{2} 、 W_{3}$ 组合权重的确定, 多数文献采用的是经验估值方法、专 家咨询及打分的方法。这里 “雾灾” 的综合风险指数测算权重系数 $W_{1}, W_{2}, W_{3}$ 暂用经验估值, 按 5 : 2: 1 的比例进行分配, 估值依据如 下: 雾灾的危害首先取决于大雾出现 的频率和强度等为表现的原生性致灾 因子的影响, 即雾灾的危险性因素,
其权重比例定为 5/8, 表明雾灾的风险 主要与大雾天气的出现概率及强度相 关; $W_{2}$ 的权重比例为 $2 / 8$, 也间接说 明雾灾风险与城市路网密集程度, 尤 其与高速路的空间地理分布特征紧密 联系, 取值表明二者之间经验化的关 联程度; $W_{3}$ 为 $1 / 8$, 体现了城市人口 等易损性因子对雾灾风险的响应程 度, 另外, 重点设施易损程度已通过 空间叠置计算在脆弱性指标中进行了 订正, 暂不统计这部分易损性指标。 文献 [8] 在针对冰雨灾害的风险指数换 算时, 采取的是 4:3:3 的比例进行 权重分配的, 冰雱这种强致灾性天气 的灾害损失程度与下垫面地物分布所 体现的承灾体脆弱性及易损性的关联 程度更高, 其承灾体种类更多更广, 而且只要下垫面存有承灾体, 最终酿 成灾害的可能性均较大。雾灾的成灾 机制相对较弱的, 它是以影响人的视 野导致判断失误，引发灾难性事故而 形成灾害的, 因此, 以路网密度、人 口密度及重点设施分布为体现的雾灾 承灾体脆弱性及易损性的权重系数不 益标识过高。

\section{3. 方法与步骤}

在北京地区图幅范围内（东经 $115.390701^{\circ}-117.515098^{\circ}$, 北纬 $\times W_{3} 39.409352^{\circ}-41.081614^{\circ}$ ），共划分了 210 行、268 列网格, 每个网格点大小 为东西跨 0.008 经距, 南北跨 0.008 纬 距。

选用北京地区 19 个观测站近 10 年的大雾观测资料, 以雾天出现的频 率及频次，测算北京地区雾灾危险性 指数, 指数分布图经网格插值计算 后, 将指数值赋值予网格单元, 计算 出的北京地区雾灾危险性指数分布如 图 1 所示。 
按高速路、国道、省道、一级- 四级公路等公路等级测算单位网格 内路网密度指数, 以此作为雾灾的脆 弱性指标，不同道路类型选用不同的 权重系数, 计算出的脆弱性指数如图 3, 从图 3 中可见北京地区的雾灾脆弱 性指数强度分布与环城路、出京高速 公路 (机场高速、八达岭、京津唐 等）的路线延伸方向一致, 这与实际 最可能发生大雾灾害的路段分布情况 基本一致, 二环、三环等环城路段的 脆弱性指数较高, 与这些路段路网密 集、人多路杂的地物分布情况相吻 合。

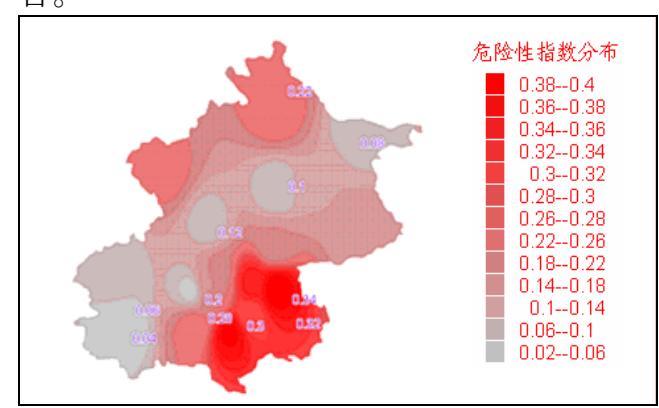

图 2 北京地区大雾危险性指数分布图

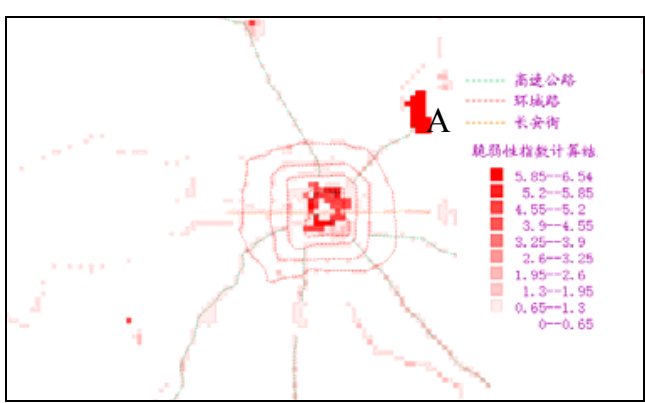

图 3 北京地区雾灾承灾体脆弱性指数（订

正）网格分布图

通过与 “机场”、“车站” 等面 或面缓冲区域的叠加对脆弱性分布图 做易损性指数订正，订正结果见图 3 (A 处), 从图中可见机场等重点设 施所处位置出现一高脆弱性区域, 这 一订正对风险结果的正确性评价是必 要的。
图 4 为通过空间演算生成的北京 地区人口密度分布图, 测算时将各网 格单元内人口密度值的归一化指数 (单网格内的人口密度除以最大人口 密度）作为易损性值, 即暂将人口密 度作为衡量城市地区灾害易损程度的 指标。

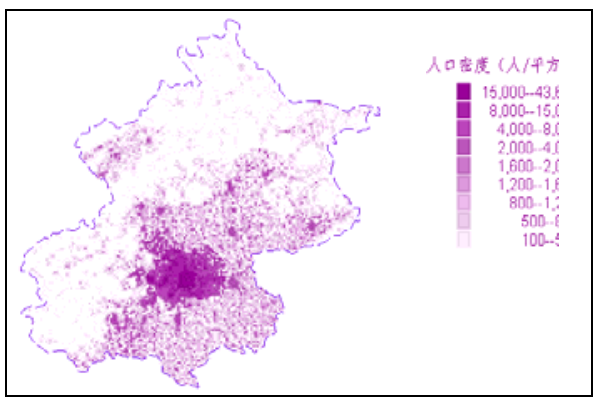

图 4 北京地区人口密度分布图

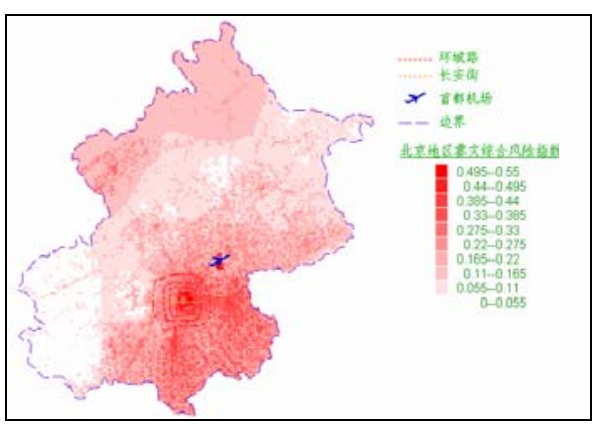

图 5 北京地区雾灾综合风险指数融合结果

图

图 5 为在危险性、脆弱性及易损 性基础上按 $5: 2: 1$ 的比值进行逐网 格单元的综合风险指数叠合计算的结 果分布图。从最终计算出的综合风险 评估结果可知, 北京地区雾灾的高风 险区域分布在高速公路、环城路等车 辆流量大、车辆行驶速度较快的区 域。城中心近几年由于城市化的发 展, 汽车尾气排放量加大等原因, 其 雾灾的风险也出现增加的趋势, 这里 路网密布，是雾灾的高风险区域，大 雾天气对这里稠密分布的市民的生活 
及健康同样带来不容忽视的影响。北 京东南部地区的雾灾风险指数同样较 大, 该地地势较低平, 水汽充沛, 相 对湿度较大, 文献[10]认为此处还受烟 尘堆积及聚集的影响, 大雾出现的频 次及强度相对较高, 是雾灾的较高风 险区域。

\section{4. 总结}

（1）根据评估网格单元内的大雾 出现的频率、频次等指标核算雾灾的 危险性指数; 对不同道路类型取不同 的权重系数, 测算路网密度, 以归一 化路网密度指数作为评估区域的雾灾 脆弱性指数, 并针对重点实施的分布 对脆弱性指数进行订正。应用实例的 图示化评估结果表明北京地区脆弱性 指数的强弱分布与环城路及高速公路 延伸方向一致, 结果与实际情况相吻 合。

（2）综合风险指数按 $5: 2: 1$ 的 比例逐网格叠加上 “雾灾” 危险性、 承灾体脆弱性及易损性指数, 指数比 例分配体现各种风险因子对 “雾灾” 成灾机制的贡献大小。照此方法测算 的北京地区雾灾风险结果表明：高速 公路、环城路段及“路网密度大、人 口稠密” 的城市中心地区为雾灾的高 风险区域; 由于特殊的地理位置，北 京东南部地区的大雾出现的频次及强 度相对较高, 是雾灾的较高风险区 域。

\section{参考文献}

[1]周淑贞,束炣.城市气候学.气象出版 社.1994.

[2]王继志,徐祥德,杨元琴.北京城市能见度 及雾特征分析.应用气象学报,2002,13:160169 .
[3] Stanley Kaplan, B.John Garrick. On The Quantitative Definition of Risk. Risk Analysis, 1(1):P11-27.

[4]何金梅,王冬梅,李晓霞.甘肃省高等级公 路沿线大雾天气气候特征及其预报服务.干 旱气象,2006,24(1):48-52.

[5]张飒,冯建设. 济青高速公路大雾天气气候 特征及其影响.气象,2005,31(2):70-89.

[6]扈海波, 王迎春, 刘伟东.气象灾害事件 的数学形态学特征及空间表现. 应用气象学 报,2007,18(6):802:809.

[7]扈海波,王迎春. 基于数学形态学方法的统 计数值空间离散化图谱生成. 计算机工

程,2007,33(21):9-11.

[8]北京市气象局灾害风险评估小组.北京市 奥运期间突发气象灾害风险评估及对策研 究. 2007, 北京市气象局.

[9] B.John Garrick. The use of risk assessment to evaluate waste disposal facilities in the United States of America. Safety Science, Volume 40, issues 1-4, February-June 2002,P135-151.

[10] 张光智, 市林根, 王继志等. 北京及周边地 区雾形成的边界层特征. 中国科学 $\mathrm{D}$ 缉 地球 科学,2005,35(增 I):73-83.

[11]WANG Jing-ai, SU Yun, et al. Vulnerability Identification and Assessment of Agriculture Drought Disaster in China. Advances in earth science,2006,21(2):161 168.

[12]郭虎,熊亚军,扈海波.北京市奥运期 间气象灾害风险承受与控制能力分析. 气象,2008,34(2):77-82. 